\title{
Prediction of Collapse Scope of Deep-Buried Tunnels Using Pressure Arch Theory
}

\author{
Yingchao Wang, ${ }^{1,2}$ Hongwen Jing, ${ }^{1,2}$ Qiang Zhang, ${ }^{1}$ Ning Luo, ${ }^{1}$ and Xin Yin ${ }^{1}$ \\ ${ }^{1}$ State Key Laboratory for Geomechanics and Deep Underground Engineering, China University of Mining and Technology, \\ Xuzhou, Jiangsu 221116, China \\ ${ }^{2}$ School of Mechanics and Civil Engineering, China University of Mining and Technology, Xuzhou, Jiangsu 221116, China
}

Correspondence should be addressed to Yingchao Wang; wych12345678@126.com

Received 16 April 2016; Accepted 20 June 2016

Academic Editor: Giovanni Garcea

Copyright (C) 2016 Yingchao Wang et al. This is an open access article distributed under the Creative Commons Attribution License, which permits unrestricted use, distribution, and reproduction in any medium, provided the original work is properly cited.

\begin{abstract}
Tunnel collapse remains a serious problem in practice. Effective prediction methods on tunnel collapse are necessary for tunnel engineering. In this study, systematic study on the pressure arch was presented to predict tunnel collapse. Multiple factors under different conditions were considered. First, the pressure arch was described as a certain scope in comparison with the lowest pressure arch line. Then, a deep-buried circular tunnel was selected as the investigated object. Its collapse scope was analyzed using the lowest pressure arch line. Meanwhile, the main influence from the ground stress field was considered. Different modes of ground stress fields were investigated in detail. The results indicate that the collapse scope varies with different ground stress fields. Determination on the collapse scope is strongly affected by the judgment standard of the pressure arch. Furthermore, a selected case was analyzed with the pressure arch. The area and the height of tunnel collapse were calculated with multiple factors, including ground stress field, judgment standard, and lateral pressure coefficient. Finally, selected results were compared with relevant previous researches, and reasonable results were obtained. The present results are helpful for further understanding of the tunnel collapse and could provide suitable guidance for tunnel projects.
\end{abstract}

\section{Introduction}

Roof collapse of underground cavities is a practical problem in geotechnical engineering, which usually arises not only in shallow tunnels but also in deep-buried tunnels. Recently, deeper and longer tunnels have been constructed or are under construction in hydropower and transportation fields in China [1]. During the construction of deep-buried tunnels, collapse frequently occurs, which leads to great economic losses and heavy casualties [2-4]. Many efforts have been made to prevent deep-buried tunnels from collapsing, including monitoring, measurement, and prediction. Meanwhile, collapse prediction for deep-buried tunnels is imperative during tunnel construction.

Deep-buried tunnels present many complicated engineering problems [5]. First, tunneling usually traverses multiple geological conditions, like deep underground strata and thick or extremely thick layered rock strata. Second, the presence of cracks and fractures in rock banks can directly induce tunnel collapse $[3,6]$. Third, tunnel collapse is strongly affected by random variation in the mechanical properties of the rock in situ. In addition, tunnel collapse can be caused not only by these natural factors [7] but also by human factors, including blast vibration [8], construction conditions, support design, and unexpected failures at work. As a result, more and more attention has been paid to tunnel collapse, particularly for deep-buried tunnels. In order to better understand tunnel collapse, much research has been done on estimating the instability of tunnel roofs and heading faces, using several approaches, including numerical simulation, experimental methods, and analytical approaches [9-11]. However, it is difficult to investigate tunnel collapse experimentally, since recent measurement techniques are limited by the multiscale complexity of the system. Numerical simulations are usually accompanied by multiple assumptions with a complex calculation process. Due to its 
feasibility and conveniences, the analytical approach has been widely employed to estimate the stability problems in tunnel engineering.

Previous studies on tunnel collapse have focused on analysis techniques, which have been proposed for evaluating the stability of tunnels and investigating the so-called arching effect for both soft soils and hard rocks [12, 13]. Meanwhile, some techniques depended on the specific prepartitioning of the soil domain with theorems of limit analysis [14]. Three independent methods were used to evaluate the roof collapse of underground rectangular cavities for a range of geometries and rock properties [15]. Moreover, an analytical upper bound method, proposed by Fraldi and Guarracino, was used to predict plastic collapse in circular rock tunnels $[6,16]$. According to Hoke-Brown failure criterion and the upper bound theorem of limit analysis, tunnel collapse under seepage forces condition and three-dimensional failure mechanism of a rectangular cavity were studied in detail [9, 17-21]. Senent et al. [22] studied the face stability of circular tunnels, which were excavated in heavily fractured and "low quality" rock masses, and the nonlinear HokeBrown (HB) failure criterion was applied. Useful results have been obtained with the abovementioned methods. However, due to the complex features of the engineering conditions, it is difficult for one method to obtain useful results when predicting collapse position and the collapse height. In addition, an accurate method of determining the loading mode has yet to be found, which should be acknowledged and could be applied to a wide range of tunnel collapses. Therefore, further research on predicting tunnel collapses is indeed necessary. To estimate the instability of tunnel roofs, a reliable and feasible method is still needed to calculate the collapse scope more accurately for deep-buried tunnels under different ground stress fields.

In practice, the main issue faced by engineering is the analysis of roof failure occurring in deep-buried tunnels [9]. It is still difficult to accurately calculate the key parameters of pressure in the surrounding rock and the relative arching mechanism is also ambiguous [23]. Meanwhile, the evolution characteristics of the pressure arch for a tunnel are difficult to determine exactly. Generally, there is a lack of theoretical solutions, not only for estimating the instability of tunnel roof, but also for predicting the scope of collapse for deep-buried tunnels, especially under different stress fields. However, there are many methods currently being investigated by engineers and researchers, including the analogue model with experience, the structural-geological model, the constrained model with convergence, and the load model. The load model is regarded as one of the most useful models for calculating the pressure of the surrounding rock in tunnel engineering. In detail, the load model involves the restrictive effect of upper strata on the surrounding rock, which is regarded as the main effect of the pressure arch. Research on the pressure arch has been conducted for a long time, but its application is very limited in some conditions.

In the present work, pressure arch theory was employed as an analysis method to predict the collapse scope in deepburied tunnels. First, the pressure arch derived from pressure arch theory is described in detail. Meanwhile, the lowest
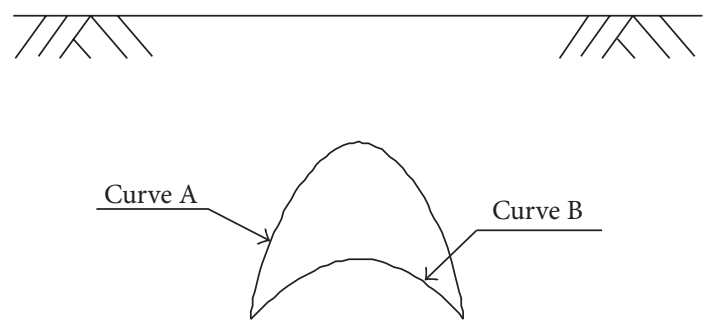

Figure 1: Pressure arch of unexcavated tunnel.

pressure arch curve is presented for prediction. Based on the lowest pressure arch, the presented pressure arch curve was applied to predict the collapse scope for a deep-buried circular tunnel. Then, the main influences of the ground stress field related to tunnel collapses were investigated. Moreover, the area and the height of the collapse scope were calculated and analyzed for the deep-buried circular tunnel. Furthermore, multiple factors, including ground stress field, judgment standard, and lateral pressure coefficient, were considered when calculating the area and height of tunnel collapse to find the tendency and variation. Selected results from the present study were compared with results obtained by other researchers. These results are helpful to estimate the overall burden on the lining and can guide further study of prediction methods for tunnel collapses.

\section{The Pressure Arch Theory}

The present pressure arch was derived from pressure arch theory but differs from that theory in key ways, which are described as follows.

Before the tunnel excavation, all the surrounding rock was under pressure due to the action of gravity. Thus, the surrounding rock along any inner curve was in a compression state along three axes, known as the triaxial compression state, as shown in Figure 1. For example, A and B are arbitrary curves of the pressure arch, which are stable.

After tunnel excavation, due to the unloading effect, the stress in the surrounding rock around the tunnel contour changes, and the surrounding rock within different scopes might have different stress levels. Thus, there is no guarantee that the surrounding rock along any arbitrary curve is in a compression state. There should be some surrounding rock in a tensile state with different tensile stress levels. Meanwhile, there exists a curve with a tensile stress of zero. This curve is used for partitioning the region of the surrounding rock above the tunnel contour, which can be divided into two main regions.

Above the curve with a tensile stress of zero, the surrounding rock within a certain scope is thought to be in the unidirectional compression state, which seems like an arch and is defined as the pressure arch in the present study. Furthermore, the curve with a tensile stress of zero is selected as the lowest pressure arch curve. Any arbitrary curve above the lowest pressure arch curve, like A in Figure 1, is called the pressure arch. On the pressure arch curve, the surrounding rock is still in a compression state, as shown in Figure 2. 


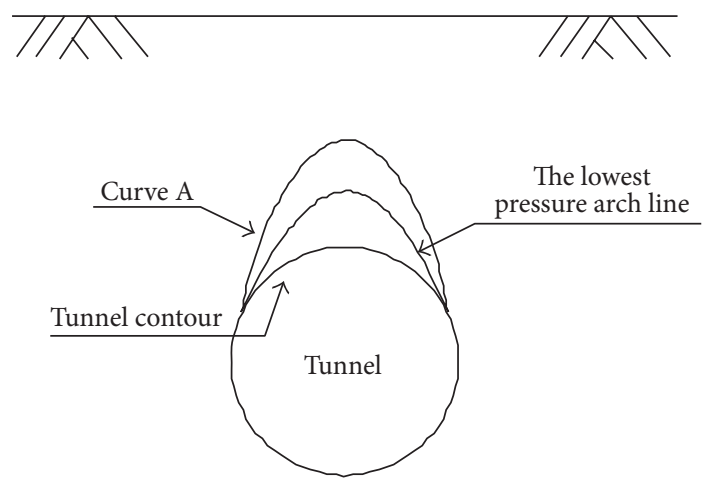

Figure 2: Pressure arch of excavated tunnel.

On the other hand, below the lowest pressure arch line, the surrounding rock within a limited scope above the tunnel contour is in a tension state with instability, since the tensile bearing capacity is low for the cracked surrounding rock. The unstable state of the surrounding rock could cause collapseinduced damage and lead to tunnel collapse. The scope of instability within the surrounding rock is regarded as the collapse scope in the present study.

According to the abovementioned analysis, the lowest pressure arch line is significant for predicting collapse of the surrounding rock, which should be gained in the first place. Then, the collapse would be gained accordingly when the area and the height of collapse scope for tunnels are obtained.

\section{Results and Discussion}

\subsection{The Pressure Arch with Bidirectional and Constant Ground Stress}

3.1.1. Results of Different Lateral Pressure Coefficients with Different Judgment Standards. The deep-buried circular tunnel was selected as the investigated object, which was analyzed under bidirectional and constant ground stress, as shown in Figure 3. The parameters to be analyzed are introduced as follows: the vertical component of nature stress for rock is $\sigma_{V}$; the horizontal component is $\sigma_{H}$; the lateral pressure coefficient is defined as $\xi=\sigma_{H} / \sigma_{V}$; the radial stress is $\sigma_{r}$; the tangential stress is $\sigma_{\theta}$; and the minimum principal stress is $\sigma_{3}$. Additionally, it was assumed that the compressed state had a positive stress value, while the tension state had a negative stress value. Tangential stress $\left(\sigma_{\theta}\right)$ occurs in the tensile state, which was selected as the judgment standard for the pressure arch. Additionally, the lateral pressure coefficient is $\xi=0.1$. Then, the lowest pressure arch line is calculated, as shown in Figure 4.

In order to calculate the scope of tunnel collapse, a plane rectangular coordinate system was established. As shown in Figure 5, there are three key points in the pressure arch line: $A(-2.8,5.2), B(2.8,5.2)$, and $C(0,9)$. The equation to determine the lowest pressure arch curve can be obtained as follows:

$$
x^{2}=-2.06(y-9) \text {. }
$$

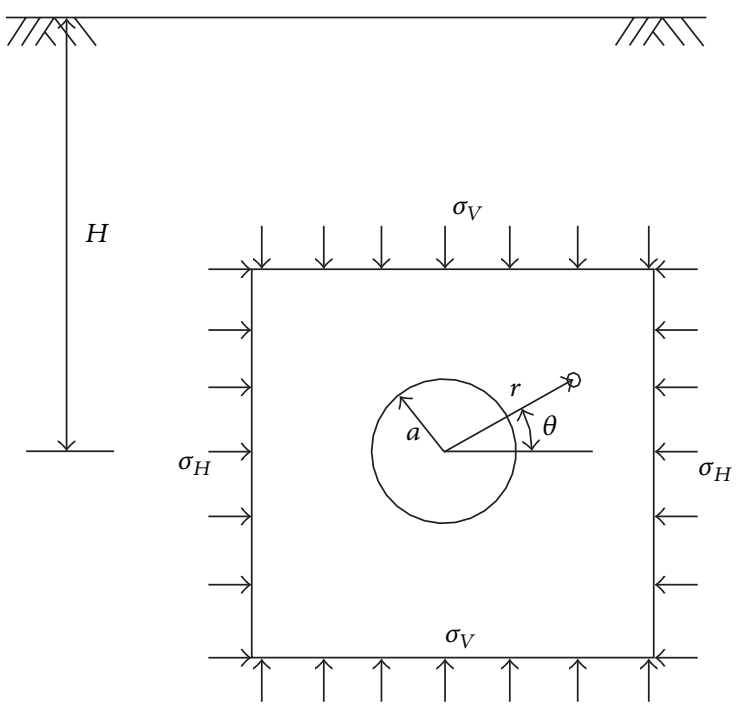

Figure 3: Deep tunnel with bidirectional and constant ground stress.
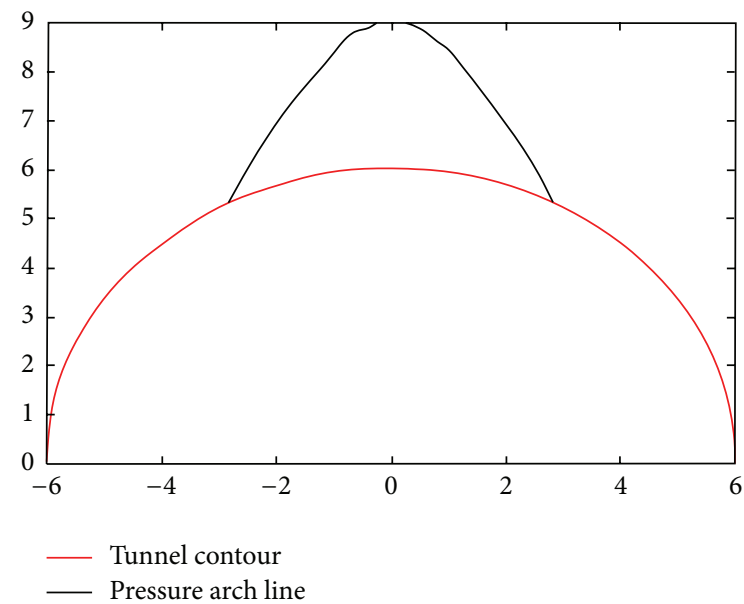

FIGURE 4: Pressure $\operatorname{arch}\left(\xi=0.1, \sigma_{\theta}<0\right.$, bidirectional and constant ground stress).

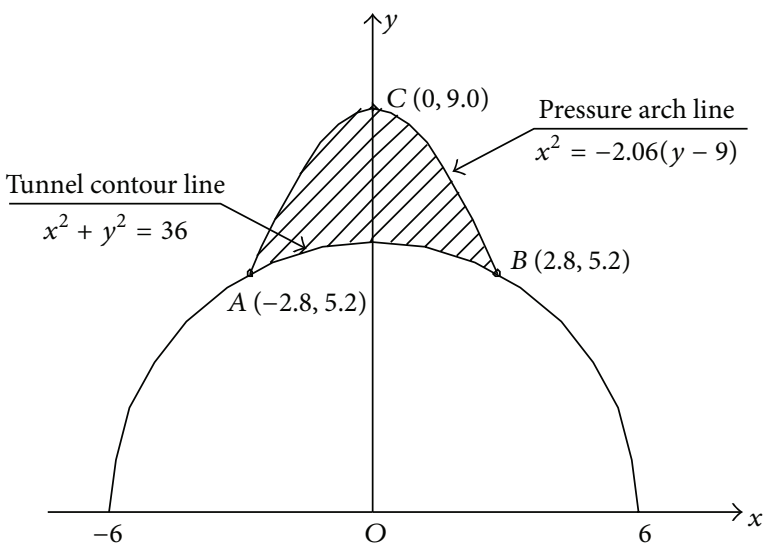

FIGURE 5: Scope of tunnel collapse $\left(\xi=0.1, \sigma_{\theta}<0\right.$, bidirectional and constant ground stress). 


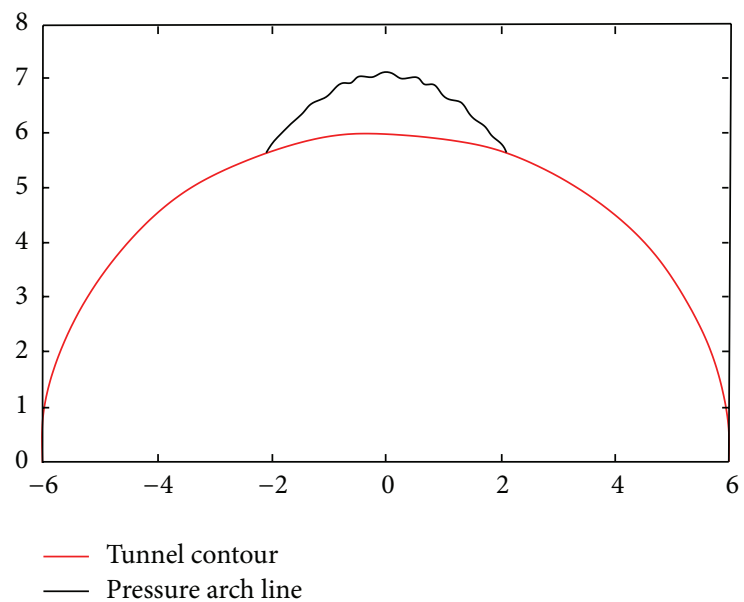

Figure 6: Pressure arch $\left(\xi=0.2, \sigma_{\theta}<0\right.$, bidirectional and constant ground stress).

Equation (1) can also be expressed as $y_{1}=-x^{2} / 2.06+9$, while the equation to determine the tunnel contour curve is presented as

$$
x^{2}+y^{2}=36
$$

Meanwhile, (2) can also be expressed as $y_{2}=\sqrt{36-x^{2}}$.

Therefore, the scope of tunnel collapse can be calculated as follows:

$$
\begin{aligned}
S & =\int_{-2.8}^{2.8}\left(y_{1}-y_{2}\right) d x \\
& =\int_{-2.8}^{2.8}\left(-\frac{x^{2}}{2.06}+9-\sqrt{36-x^{2}}\right) d x=10.96 \mathrm{~m}^{2} .
\end{aligned}
$$

Accordingly, the average height of tunnel collapse can be calculated as follows:

$$
h_{\mathrm{avg}}=\frac{10.96 \mathrm{~m}^{2}}{5.6 \mathrm{~m}}=1.96 \mathrm{~m} \text {. }
$$

When the tangential stress $\left(\sigma_{\theta}\right)$ in the tensile state is selected as the judgment standard of the pressure arch and the lateral pressure coefficient is $\xi=0.2$, the pressure arch curve appears as shown in Figure 6. According to the abovementioned calculation, the maximum height of tunnel collapse is $1 \mathrm{~m}$, the area of tunnel collapse is $2.05 \mathrm{~m}^{2}$, and the average height of tunnel collapse is $h_{\mathrm{avg}}=2.05 \mathrm{~m}^{2} / 4 \mathrm{~m}=$ $0.5125 \mathrm{~m}$.

When the tangential stress $\left(\sigma_{\theta}\right)$ in the tensile state is selected as the judgment standard of the pressure arch and the lateral pressure coefficient is $\xi=1 / 3$, the pressure arch curve appears as shown in Figure 7. It is possible for the pressure arch curve and the tunnel contour to coincide with each other.

When the minimum principal stress $\left(\sigma_{3}\right)$ in a state of tension is selected as the judgment standard of the pressure arch and the lateral pressure coefficient is $\xi=1 / 3$, the pressure arch curve is the same as in Figure 7, and the surrounding rock is in the compression state. When

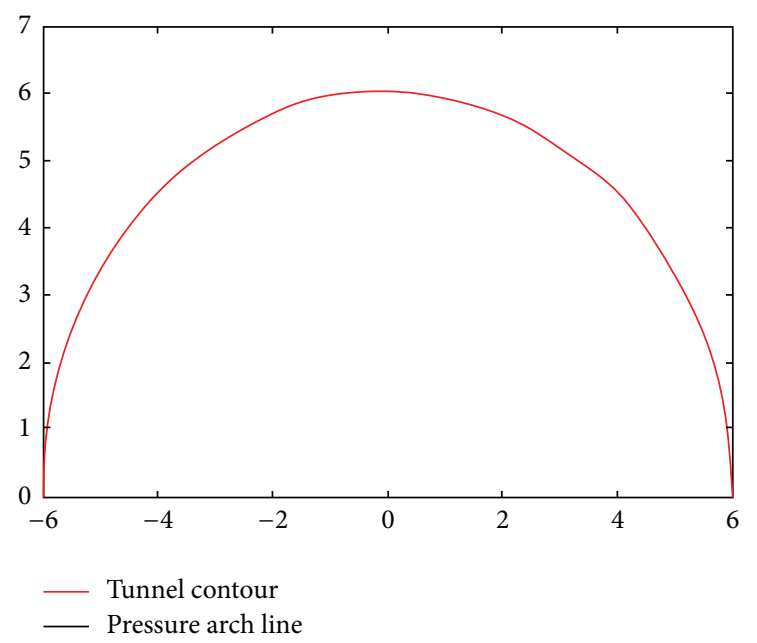

FIGURE 7: Pressure $\operatorname{arch}\left(\xi=1 / 3, \sigma_{\theta}<0\right.$, bidirectional and constant ground stress).

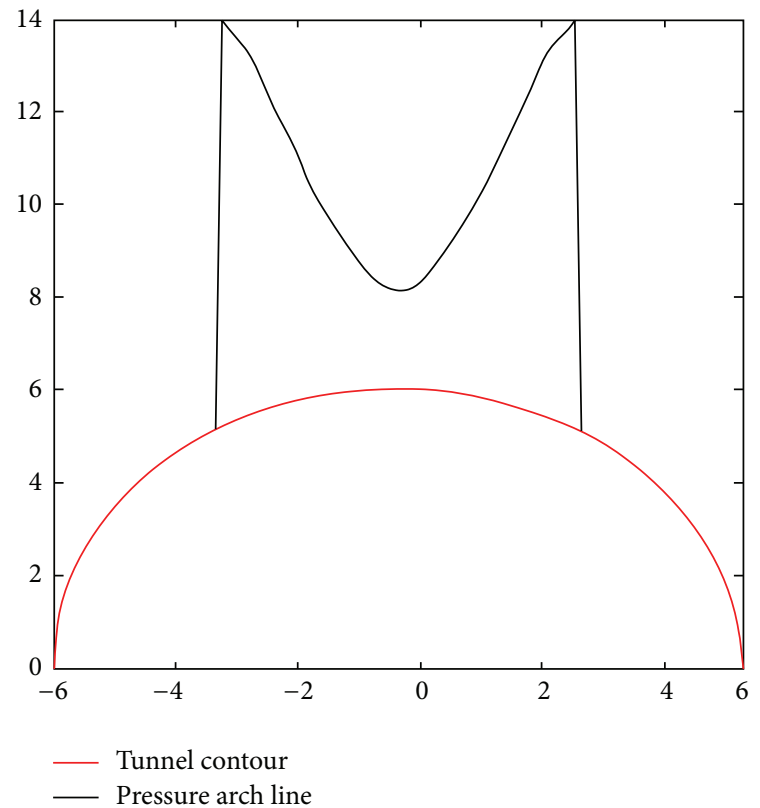

Figure 8: Pressure $\operatorname{arch}\left(\xi=0.1, \sigma_{3}<0\right.$, bidirectional and constant ground stress).

the lateral pressure coefficient $\xi$ is 0.1 , the pressure arch curve appears as shown in Figure 8.

In order to calculate the area of tunnel collapse, a plane rectangular coordinate system was established. As shown in Figure 9, there are three key points in pressure arch line, $C(0,8), D(-3.1,14), E(3.1,14)$, and the equation related to the pressure arch line can be obtained as follows:

$$
x^{2}=1.6(y-8) .
$$

Equation (5) is changed to $y_{1}=x^{2} / 1.6+8$, and the equation related to the tunnel contour curve is

$$
x^{2}+y^{2}=36 \text {. }
$$




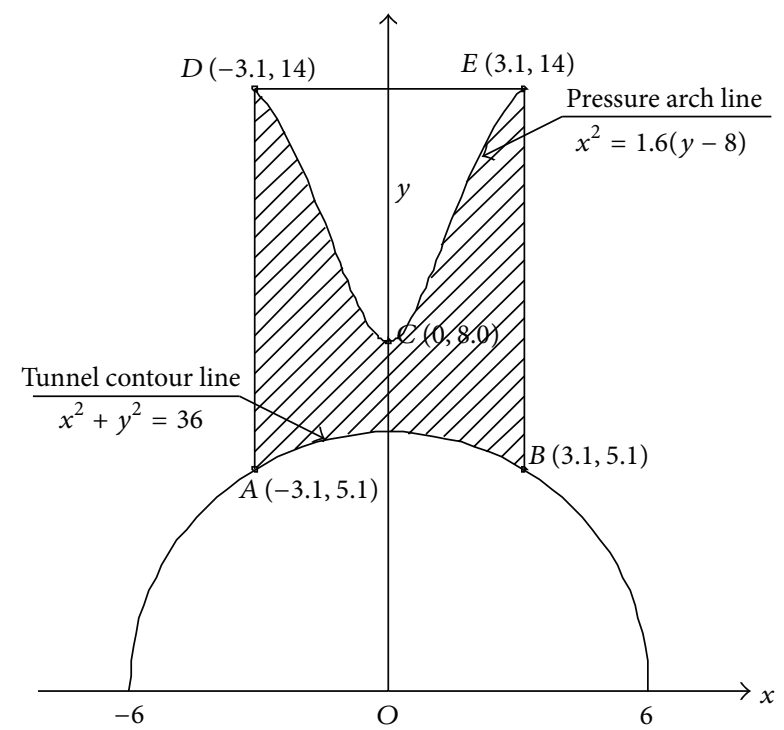

FIGURE 9: Calculation of scope of pressure $\operatorname{arch}\left(\xi=0.1, \sigma_{3}<0\right.$, bidirectional and constant ground stress).

In another form, (6) can be presented as $y_{2}=\sqrt{36-x^{2}}$. Thus, the collapse area can be calculated as

$$
\begin{aligned}
S & =\int_{-3.1}^{3.1}\left(y_{1}-y_{2}\right) d x \\
& =\int_{-3.1}^{3.1}\left(\frac{x^{2}}{1.6}+8-\sqrt{36-x^{2}}\right) d x=26.54 \mathrm{~m}^{2} .
\end{aligned}
$$

Thus, the maximum height of tunnel collapse is $10.9 \mathrm{~m}$, and the average height of tunnel collapse is $h_{\text {avg }}=$ $26.54 \mathrm{~m}^{2} / 6.2 \mathrm{~m}=4.28 \mathrm{~m}$.

When the tangential stress $\sigma_{3}$ in the tensile state is selected as the judgment standard of the pressure arch, the lateral pressure coefficient is $\xi=0.2$, and the pressure arch line is shown in Figure 10. According to the abovementioned calculating process, the maximum height of tunnel collapse is equal to $3.6 \mathrm{~m}$, the area of tunnel collapse is equal to $13.38 \mathrm{~m}^{2}$, and the average height of tunnel collapse is $h_{\text {avg }}=$ $13.38 \mathrm{~m}^{2} / 5.4 \mathrm{~m}=2.48 \mathrm{~m}$.

3.1.2. Comparison of Results under Different Conditions. According to the abovementioned analysis, when the vertical stress is three times greater than the horizontal stress $(\xi<$ $1 / 3$ ), the tunnel vault would undergo tensile stress. The area undergoing tensile stress increases as the lateral pressure coefficient $(\xi)$ decreases.

The effect of the lateral pressure coefficient $(\xi)$ on collapse scope is shown in Figure 11, and the effect of the lateral pressure coefficient $(\xi)$ on collapse height is shown in Figure 12. As shown in Figure 11, the collapse scope decreases as the lateral pressure coefficient $(\xi)$ increases. When the lateral pressure coefficient $(\xi)$ is $1 / 3$, the collapse scope is 0 . When the tangential stress $\left(\sigma_{3}\right)$ in the tensile state is selected as the judgment standard of the pressure arch, the relationship between collapse scope and the lateral pressure coefficient $(\xi)$

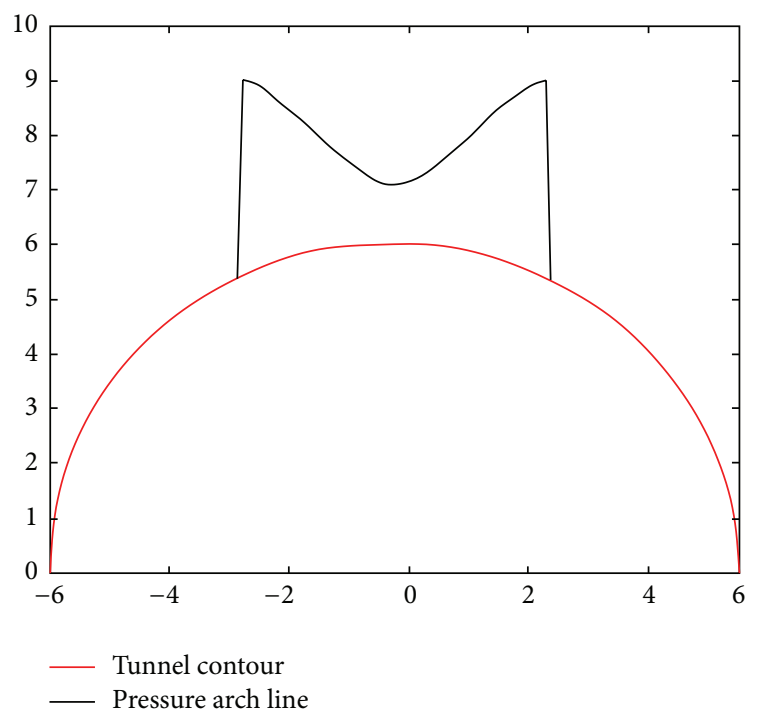

FIGURE 10: Pressure arch (when $\xi=0.1, \sigma_{3}<0$, bidirectional and constant ground stress).

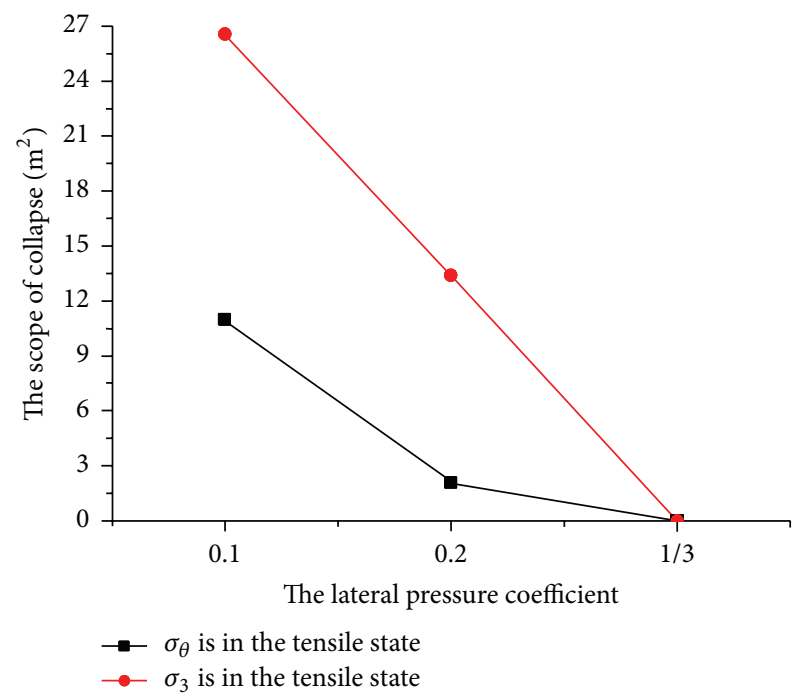

FIGURE 11: Effects of the lateral pressure coefficient on the collapse scope.

exhibits a linear tendency. Collapse height increases with the lateral pressure coefficient, as shown in Figure 12.

It is important to note that the judgment standard of the pressure arch has a great influence on the pressure arch curve. When the minimum principal stress $\left(\sigma_{3}\right)$ in tension is selected as the judgment standard, the collapse scope is much larger than that of tangential stress $\left(\sigma_{\theta}\right)$ in tension.

When the horizontal stress is too high, the definition of $\xi$ can be changed from $\sigma_{H} / \sigma_{V}$ to $\sigma_{V} / \sigma_{H}$, and the rock mass in a tensile state will occur at the waist of the arch. 


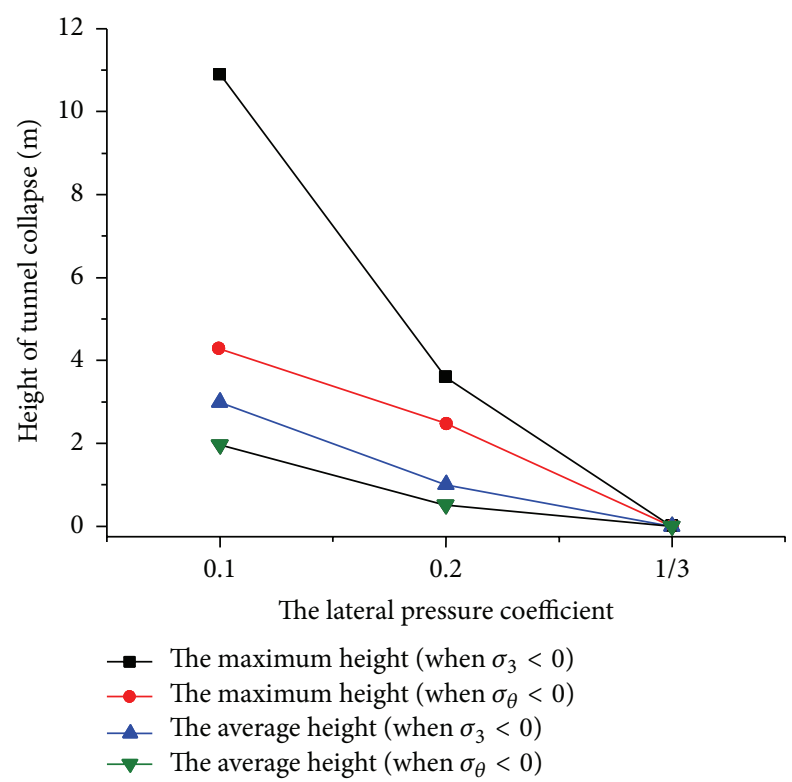

FIGURE 12: Effects of the lateral pressure coefficient on the collapse height.

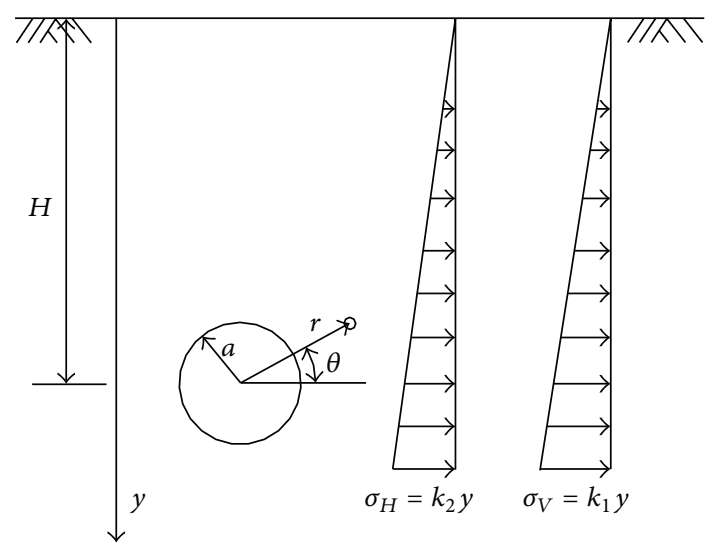

FIGURE 13: Deep tunnel with the ground stress proportional to the depth.

\subsection{The Pressure Arch with the Ground Stress \\ Proportional to the Depth}

3.2.1. The Theoretical Results of Ground Stress. As shown in Figure 13, the ground stress is proportional to the depth for a deep-buried circular tunnel. The stress field of surrounding rock with gravity has been solved using functions of complex variables [24]. In this study, the stress field of surrounding rock with any linear ratio was calculated using the elastic mechanics method.

(1) Original Stress Field of Surrounding Rock before Tunnel Excavation. The stress field in Cartesian coordinates was converted to polar coordinates, and the results are shown as follows:

$$
\begin{aligned}
\sigma_{r 0}= & \frac{\left(k_{1}+k_{2}\right) H}{2}-\frac{\left(3 k_{1}+k_{2}\right) r \sin \theta}{4} \\
& -\frac{\left(k_{1}-k_{2}\right) H \cos 2 \theta}{2}+\frac{\left(k_{1}-k_{2}\right) r \sin 3 \theta}{4} \\
\sigma_{\theta 0}= & \frac{\left(k_{1}+k_{2}\right) H}{2}-\frac{\left(k_{1}-k_{2}\right) r \sin \theta}{4} \\
& +\frac{\left(k_{1}-k_{2}\right) r \sin 3 \theta}{4} \\
\tau_{r \theta 0}= & -\frac{\left(k_{1}-k_{2}\right) r \cos \theta}{4}+\frac{\left(k_{1}-k_{2}\right) H \sin 2 \theta}{2} \\
& +\frac{\left(k_{1}-k_{2}\right) r \cos 3 \theta}{4},
\end{aligned}
$$

where $\sigma_{r 0}, \sigma_{\theta 0}$, and $\tau_{r \theta 0}$ are radial stress, tangential stress, and shear stress for Point 0 , respectively. $H$ is the buried depth of central tunnel, $k_{1}$ represents the ratio of the vertical stress to the depth, and $k_{2}$ represents the ratio between the horizontal stress and the depth. In addition, $r$ is the polar radius, and $\theta$ is the polar angle.

(2) Unloading after Tunnel Excavation. After tunnel excavation, the unloading of the working face, $r=a$, can be divided into four parts as follows:

The first part: $\sigma_{r}=-\frac{\left(k_{1}+k_{2}\right) H}{2}$,

$$
\tau_{r \theta}=0
$$

The second part: $\sigma_{r}=\frac{\left(3 k_{1}+k_{2}\right) a \sin \theta}{4}$,

$$
\tau_{r \theta}=\frac{\left(k_{1}-k_{2}\right) a \cos \theta}{4} ;
$$

The third part: $\sigma_{r}=\frac{\left(k_{1}-k_{2}\right) H \cos 2 \theta}{2}$,

$$
\tau_{r \theta}=-\frac{\left(k_{1}-k_{2}\right) H \sin 2 \theta}{2} ;
$$

The fourth part: $\sigma_{r}=-\frac{\left(k_{1}-k_{2}\right) a \sin 3 \theta}{4}$,

$$
\tau_{r \theta}=-\frac{\left(k_{1}-k_{2}\right) a \cos 3 \theta}{4} .
$$

(i) The first part of the stress field induced by unloading is as follows:

$$
\begin{aligned}
\sigma_{r 1} & =-\frac{a^{2}\left(k_{1}+k_{2}\right) H}{2 r^{2}}, \\
\sigma_{\theta 1} & =\frac{a^{2}\left(k_{1}+k_{2}\right) H}{2 r^{2}}, \\
\tau_{r \theta 1} & =0 .
\end{aligned}
$$


(ii) The second part of the stress field induced by unloading is as follows:

$$
\begin{aligned}
\sigma_{r 2} & =\left\{\frac{(3+\mu) k_{1} a^{2}}{4 r}+\frac{\left(k_{2}-\mu k_{1}\right) a^{4}}{4 r^{3}}\right\} \sin \theta, \\
\sigma_{\theta 2} & =\left\{-\frac{(1-\mu) k_{1} a^{2}}{4 r}-\frac{\left(k_{2}-\mu k_{1}\right) a^{4}}{4 r^{3}}\right\} \sin \theta, \\
\tau_{r \theta 2} & =\left\{\frac{(1-\mu) k_{1} a^{2}}{4 r}-\frac{\left(k_{2}-\mu k_{1}\right) a^{4}}{4 r^{3}}\right\} \cos \theta .
\end{aligned}
$$

(iii) The third part of the stress field induced by unloading is as follows:

$$
\begin{aligned}
& \sigma_{r 3}=\left[\frac{2\left(k_{1}-k_{2}\right) H a^{2}}{r^{2}}-\frac{3\left(k_{1}-k_{2}\right) H a^{4}}{2 r^{4}}\right] \cos 2 \theta, \\
& \sigma_{\theta 3}=\frac{3\left(k_{1}-k_{2}\right) H a^{4}}{2 r^{4}} \cos 2 \theta, \\
& \tau_{r \theta 3}=\left[\frac{\left(k_{1}-k_{2}\right) H a^{2}}{r^{2}}-\frac{3\left(k_{1}-k_{2}\right) H a^{4}}{2 r^{4}}\right] \sin 2 \theta .
\end{aligned}
$$

(iv) The fourth part of the stress field induced by unloading is as follows:

$$
\begin{gathered}
\sigma_{r 4}=\left[-\frac{5\left(k_{1}-k_{2}\right) a^{4}}{4 r^{3}}+\frac{\left(k_{1}-k_{2}\right) a^{6}}{r^{5}}\right] \sin 3 \theta, \\
\sigma_{\theta 4}=\left[\frac{\left(k_{1}-k_{2}\right) a^{4}}{4 r^{3}}-\frac{\left(k_{1}-k_{2}\right) a^{6}}{r^{5}}\right] \sin 3 \theta, \\
\tau_{r \theta 4}=\left[\frac{3\left(k_{1}-k_{2}\right) a^{4}}{4 r^{3}}-\frac{\left(k_{1}-k_{2}\right) a^{6}}{r^{5}}\right] \cos 3 \theta .
\end{gathered}
$$

(3) The Total Stress Field of Surrounding Rock after Tunnel Excavation. The original stress field and the stress field induced by unloading can be added, and the total stress field after excavation can be obtained as follows:

$$
\begin{aligned}
\sigma_{r} & =\sigma_{r 0}+\sigma_{r 1}+\sigma_{r 2}+\sigma_{r 3}+\sigma_{r 4}, \\
\sigma_{\theta} & =\sigma_{\theta 0}+\sigma_{\theta 1}+\sigma_{\theta 2}+\sigma_{\theta 3}+\sigma_{\theta 4}, \\
\tau_{r \theta} & =\tau_{r \theta 0}+\tau_{r \theta 1}+\tau_{r \theta 2}+\tau_{r \theta 3}+\tau_{r \theta 4} .
\end{aligned}
$$

3.2.2. Case Study. In order to analyze the pressure arch in detail, a deep-buried circular tunnel was selected as an example. For the tunnel, the buried depth $H$ was $600 \mathrm{~m}$, the radius was $6 \mathrm{~m}$, and the rock mass density $\gamma$ was $25 \mathrm{kN} / \mathrm{m}^{3}$ $\left(k_{2}=25 \mathrm{kN} / \mathrm{m}^{3}\right)$. The coefficients of lateral pressure with respect to $k_{1}$ and $k_{2}$ were assigned values of 0.1 and 0.2 , respectively. Poisson's ratio of rock $\mu$ was 0.2 .

When the tangential stress in tension state was selected as the judgment standard of the pressure arch, the typical pressure arch was presented, as shown in Figure 14. There is an obvious difference between tectonic stress fields with and

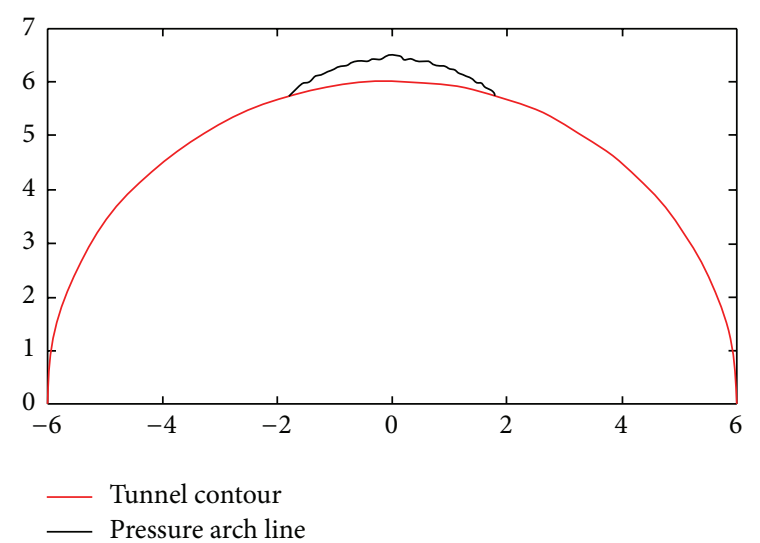

Figure 14: Pressure arch $\left(\xi=0.1, \sigma_{\theta}<0\right.$, proportional ground stress).

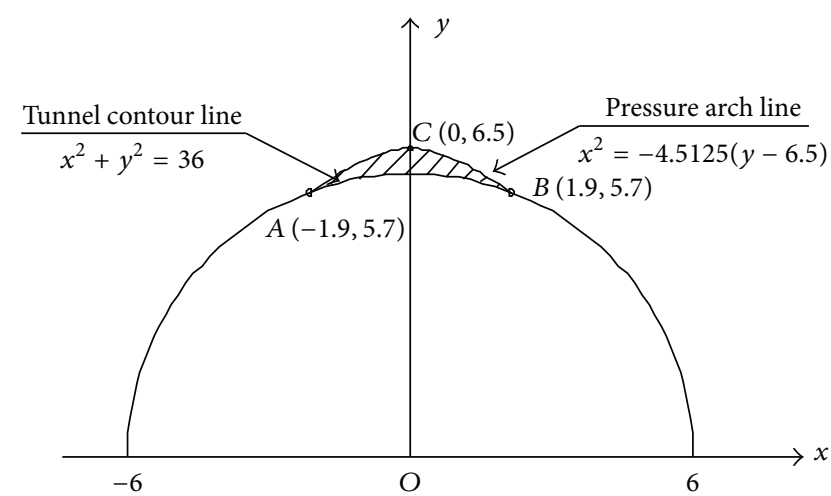

FIgURE 15: Scope of tunnel collapse $\left(\xi=0.1, \sigma_{\theta}<0\right.$, proportional ground stress).

without gradient. For the tectonic stress field with gradient, the value of $\xi$ with tensile stress and tensile scope all decreases obviously when compared with that of the tectonic stress field without gradient.

In order to gain the scope of tunnel collapse, a plane rectangular coordinate system was established. As shown in Figure 15, there are three points in pressure arch line, $A(-1.9,5.7), B(1.9,5.7)$, and $C(0,6.5)$, and the equation related to the pressure arch line can be obtained as follows:

$$
x^{2}=-4.5125(y-6.5) \text {. }
$$

With another form, (15) can be presented as $y_{1}=-x^{2} /$ $4.5125+6.5$.

The equation relative to tunnel contour line can be described as

$$
x^{2}+y^{2}=36
$$

With another form, (16) can be presented as $y_{2}=$ $\sqrt{36-x^{2}}$. 


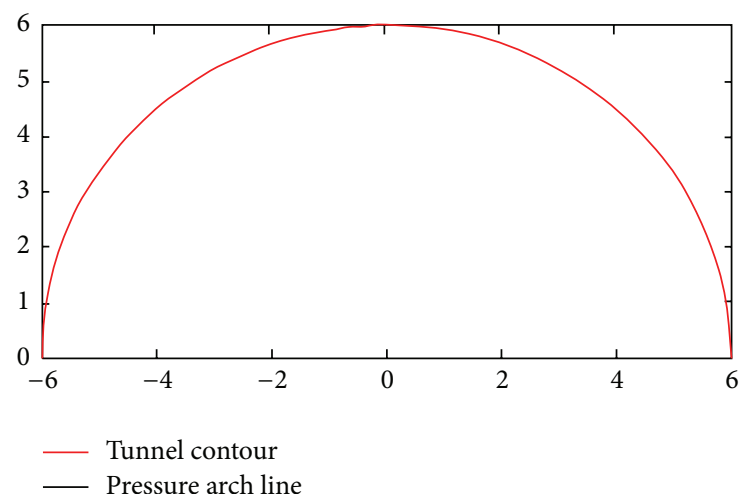

Figure 16: Pressure $\operatorname{arch}\left(\xi=0.2, \sigma_{\theta}<0\right.$, proportional ground stress).

Then, the area of tunnel collapse can be calculated as

$$
\begin{aligned}
S & =\int_{-1.9}^{1.9}\left(y_{1}-y_{2}\right) d x \\
& =\int_{-1.9}^{1.9}\left(-\frac{x^{2}}{4.5125}+6.5-\sqrt{36-x^{2}}\right) d x=1.27 \mathrm{~m}^{2} .
\end{aligned}
$$

Therefore, the maximum height of tunnel collapse is equal to $0.5 \mathrm{~m}$, the area is equal to $1.27 \mathrm{~m}^{2}$, and the average height of tunnel collapse is $h_{\text {avg }}=1.27 \mathrm{~m}^{2} / 3.8 \mathrm{~m}=0.33 \mathrm{~m}$.

When the minimum principal stress in tension state was selected as the judgment standard of the pressure arch, the pressure arch of $\xi=0.2$ is shown in Figure 16, while the pressure arch of $\xi=0.1$ is presented in Figure 17 .

In order to gain the scope of tunnel collapse, a plane rectangular coordinate system was established. As shown in Figure 18, there are five key points in pressure arch line: $A(-1.9,5.7), B(1.9,5.7), C(0,7), D(-1.9,8.2)$, and $E(1.9,8.2)$. The maximum height of tunnel collapse is equal to $2.5 \mathrm{~m}$, and the equation relation of the pressure arch line can be obtained as follows:

$$
x^{2}=3.008(y-7) \text {. }
$$

With another form, (18) can be presented as $y_{1}=$ $x^{2} / 3.008+7$.

The equation relative to tunnel contour line is

$$
x^{2}+y^{2}=36
$$

Equation (19) can be changed to another form; that is, $y_{2}=\sqrt{36-x^{2}}$. Thus, the scope of tunnel collapse can be calculated as

$$
\begin{aligned}
S & =\int_{-1.9}^{1.9}\left(y_{1}-y_{2}\right) d x \\
& =\int_{-1.9}^{1.9}\left(\frac{x^{2}}{3.008}+7-\sqrt{36-x^{2}}\right) d x=2.57 \mathrm{~m}^{2} .
\end{aligned}
$$

Therefore, the average height of tunnel collapse is $h_{\mathrm{avg}}=$ $2.57 \mathrm{~m}^{2} / 3.8 \mathrm{~m}=0.68 \mathrm{~m}$.

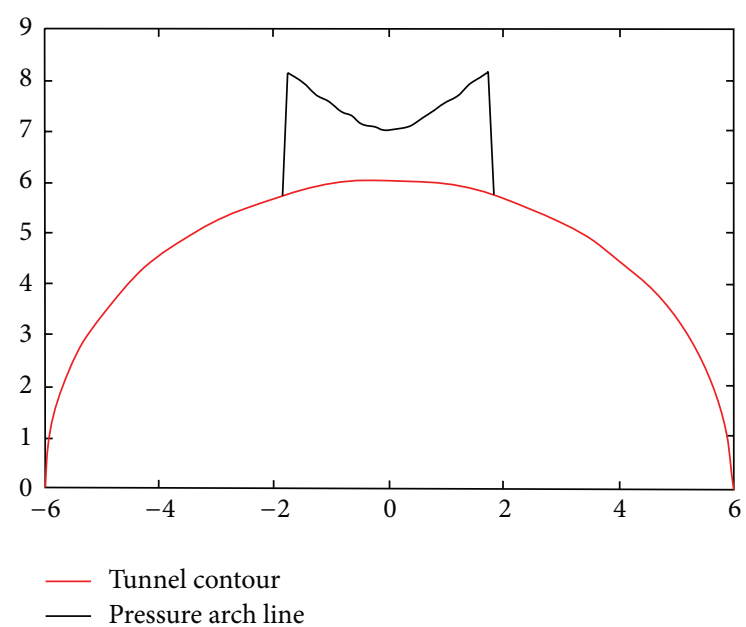

FIGURE 17: Pressure arch $\left(\xi=0.1, \sigma_{3}<0\right.$, proportional ground stress).

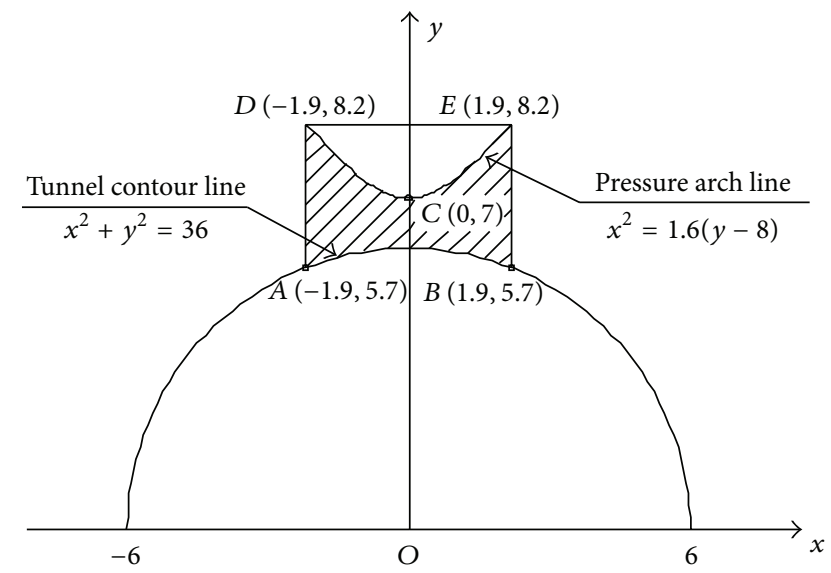

FIGURE 18: Scope of tunnel collapse $\left(\xi=0.1, \sigma_{3}<0\right.$, proportional ground stress).

\section{Comparison of Research Results}

4.1. Comparison between Different Ground Stresses. For the area and height of collapse, comparisons between different ground stresses were presented. As shown in Figure 19, there exists an obvious difference between bidirectional ground stress and proportional ground stress. Furthermore, ground stress has an obvious effect on the area and height of collapse. The collapse area is the largest under bidirectional ground stress when the minimum principal stress in tension state is selected as the judgment standard of the pressure arch. However, the scope of collapse is the smallest under proportional ground stress when the tangential stress in tension state is selected as the judgment standard of the pressure arch. Moreover, the variation tendencies for the maximum height and average height are similar to that of the collapse area changing with different ground stresses.

Therefore, when the minimum principal stress in tension is selected as the judgment standard, the area of the tensile area is obviously larger than that when tangential stress in 


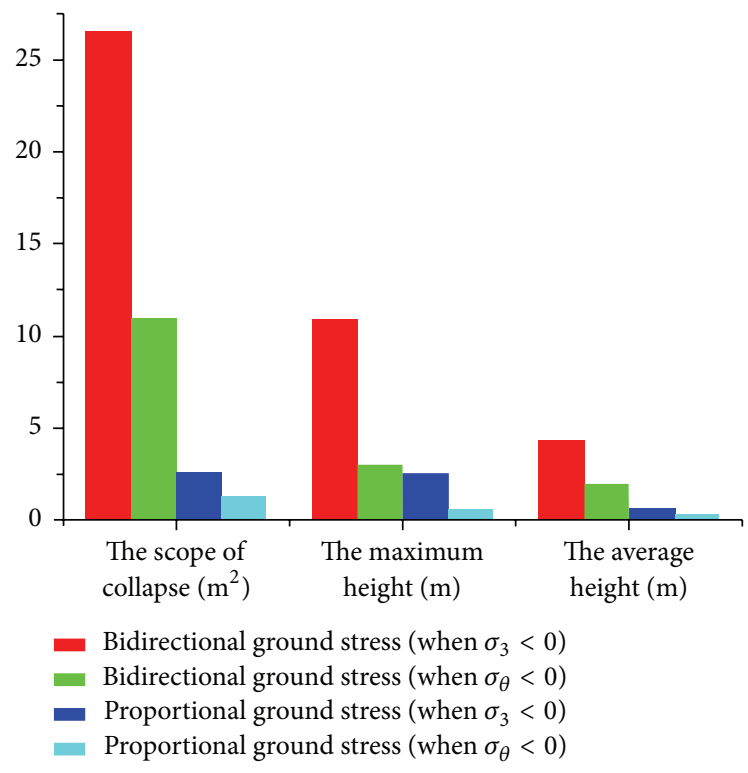

FIGURE 19: The comparison of different ground stresses $(\xi=0.1)$.

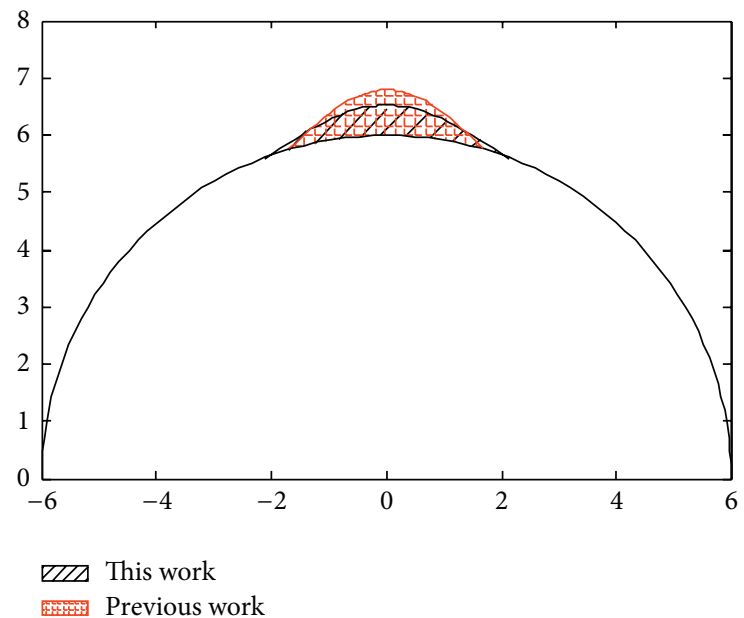

FIgURE 20: Comparison between the present result and the relative results of collapse area for deep circular tunnel.

tension is selected as the judgment standard. Considering engineering safety, the minimum principal stress in tension is the better judgment standard when analyzing the pressure arch.

4.2. Comparison with Previous Work. In order to verify the proposed method, the results were compared with previous studies. Selected conditions were presented for comparison, and the area of tunnel collapse was calculated based on the pressure arch theory. The corresponding parameters are shown as follows: runnel radius is $r=6 \mathrm{~m}$, rock mass density is $\gamma=25 \mathrm{kN} / \mathrm{m}^{3}$, the buried depth is $H=600 \mathrm{~m}$, the coefficient of lateral pressure $\xi$ is 0.1 , and rock Poisson's ratio $\mu$ is equal to 0.2 . The result is presented in Figure 20.
Fraldi and Guarracino [6] have also investigated a similar circular tunnel and obtained the area of collapse scope with varying tunnel radius (Figure 20), which could be used as a comparison to validate the present model. As shown in the figure, the collapse scope in the present study approximates to that of Fraldi and Guarracino. It indicates that the results derived in the present study agree with that of previous studies to predict the collapse scope in deep-buried circular tunnels. The present method could be used to effectively predict tunnel collapse.

\section{Conclusion}

With the consideration of the serious problem with tunnel collapses, the method with the pressure arch was put forward to predict tunnel collapse in the present work. The method was presented with the lowest pressure arch line, which was used to analyze the collapse scope for a deep-buried circular tunnel. Then, the main influence from ground stress field was considered with different conditions: the ground stress proportional to the depth and the bidirectional and constant ground stress. Moreover, the area and the height of tunnel collapse were calculated in detail with the consideration of multiple factors, like ground stress field, judgment standard, and lateral pressure coefficient. It was found that the scope of tunnel collapse differs with different modes of ground stress field, and the collapse scopeis closely related to the judgment standard for the pressure arch. For bidirectional ground stress, the collapse scope decreases with the increasing of the lateral pressure coefficient. For the area and the height of collapse, there exist obvious differences between bidirectional ground stress and proportional ground stress, and the ground stress has an obvious effect on the area and the height of collapse. Furthermore, in order to verify the proposed method, corresponding comparison was presented with the previous findings, and suitable agreements could be gained. The results are significant for further understanding of the essence of tunnel collapse, which could provide more suitable guidance for future tunnel projects.

\section{Nomenclature}

$h_{\text {avg: }}$ The average height of tunnel collapse (m)

$H$ : The buried depth of central tunnel (m)

$k_{1}$ : The ratio of the vertical stress to the depth

$k_{2}$ : The ratio of the horizontal stress to the depth

$S: \quad$ The area of tunnel collapse $\left(\mathrm{m}^{2}\right)$

$r$ : The polar radius $(\mathrm{m})$

$\gamma: \quad$ The rock mass density $\left(\mathrm{kg} / \mathrm{m}^{3}\right)$

$\theta: \quad$ The polar angle $\left({ }^{\circ}\right)$

$\mu$ : Rock Poisson's ratio

$\xi: \quad$ The lateral pressure coefficient

$\sigma_{3}:$ The minimum principal stress $(\mathrm{Pa})$

$\sigma_{H}$ : The horizontal component of nature stress $(\mathrm{Pa})$

$\sigma_{V}:$ The vertical component of nature stress $(\mathrm{Pa})$

$\sigma_{r}:$ The radial stress $(\mathrm{Pa})$

$\sigma_{\theta}$ : The tangential stress $(\mathrm{Pa})$. 


\section{Competing Interests}

The authors declare that there are no competing interests regarding the publication of this paper.

\section{Acknowledgments}

Financial supports from the Fundamental Research Funds for the Central Universities (no. 2014QNB37) and the National Natural Science Foundation of China (no. 41572263 and no. 11502282) are sincerely acknowledged.

\section{References}

[1] T. H. Ma, C. A. Tang, L. X. Tang, W. D. Zhang, and L. Wang, "Rockburst characteristics and microseismic monitoring of deep-buried tunnels for Jinping II Hydropower Station," Tunnelling and Underground Space Technology, vol. 49, pp. 345368, 2015.

[2] A. Aydin, A. Ozbek, and I. Cobanoglu, "Tunnelling in difficult ground: a case study from Dranaz tunnel, Sinop, Turkey," Engineering Geology, vol. 74, no. 3-4, pp. 293-301, 2004.

[3] H.-S. Shin, Y.-C. Kwon, Y.-S. Jung, G.-J. Bae, and Y.-G. Kim, "Methodology for quantitative hazard assessment for tunnel collapses based on case histories in Korea," International Journal of Rock Mechanics and Mining Sciences, vol. 46, no. 6, pp. 10721087, 2009.

[4] J.-H. Shin, I.-K. Lee, Y.-H. Lee, and H.-S. Shin, "Lessons from serial tunnel collapses during construction of the Seoul subway line 5," Tunnelling and Underground Space Technology, vol. 21, no. 3-4, pp. 296-297, 2006.

[5] D.-F. Chen, X.-T. Feng, D.-P. Xu, Q. Jiang, C.-X. Yang, and P.P. Yao, "Use of an improved ANN model to predict collapse depth of thin and extremely thin layered rock strata during tunnelling," Tunnelling and Underground Space Technology, vol. 51, pp. 372-386, 2016.

[6] M. Fraldi and F. Guarracino, "Evaluation of impending collapse in circular tunnels by analytical and numerical approaches," Tunnelling and Underground Space Technology, vol. 26, no. 4, pp. 507-516, 2011.

[7] L. P. Li, Q. H. Wang, S. C. Li et al., "Cause analysis of soft and hard rock tunnel collapse and information management," Polish Journal of Environmental Studies, vol. 23, pp. 1227-1233, 2014.

[8] D. Uystepruyst and F. Monnoyer, "A numerical study of the evolution of the blast wave shape in rectangular tunnels," Journal of Loss Prevention in the Process Industries, vol. 34, pp. 225-231, 2014.

[9] C. B. Qin, X. L. Yang, Q. J. Pan, Z. B. Sun, L. L. Wang, and T. Miao, "Upper bound analysis of progressive failure mechanism of tunnel roofs in partly weathered stratified Hoek-Brown rock masses," International Journal of Rock Mechanics and Mining Sciences, vol. 74, pp. 157-162, 2015.

[10] R. Bubbico, B. Mazzarotta, and N. Verdone, "CFD analysis of the dispersion of toxic materials in road tunnels," Journal of Loss Prevention in the Process Industries, vol. 28, pp. 47-59, 2014.

[11] C. Vianello, B. Fabiano, E. Palazzi, and G. Maschio, "Experimental study on thermal and toxic hazards connected to fire scenarios in road tunnels," Journal of Loss Prevention in the Process Industries, vol. 25, no. 4, pp. 718-729, 2012.

[12] C. J. Lee, B. R. Wu, H. T. Chen, and K. H. Chiang, "Tunnel stability and arching effects during tunneling in soft clayey soil,"
Tunnelling and Underground Space Technology, vol. 21, no. 2, pp. 119-132, 2006.

[13] A. S. Osman, R. J. Mair, and M. D. Bolton, "On the kinematics of 2D tunnel collapse in undrained clay," Geotechnique, vol. 56, no. 9, pp. 585-595, 2006.

[14] A. Drescher and E. Detournay, "Limit load in translational failure mechanisms for associative and non-associative materials," Geotechnique, vol. 43, no. 3, pp. 443-456, 1993.

[15] A. M. Suchowerska, R. S. Merifield, J. P. Carter, and J. Clausen, "Prediction of underground cavity roof collapse using the Hoek-Brown failure criterion," Computers and Geotechnics, vol. 44, pp. 93-103, 2012.

[16] M. Fraldi and F. Guarracino, "Limit analysis of collapse mechanisms in cavities and tunnels according to the Hoek-Brown failure criterion," International Journal of Rock Mechanics and Mining Sciences, vol. 46, no. 4, pp. 665-673, 2009.

[17] C.-B. Qin, Z.-B. Sun, and Q. Liang, "Limit analysis of roof collapse in tunnels under seepage forces condition with threedimensional failure mechanism," Journal of Central South University, vol. 20, no. 8, pp. 2314-2322, 2013.

[18] F. Huang, C.-B. Qin, and S.-C. Li, "Determination of minimum cover depth for shallow tunnel subjected to water pressure," Journal of Central South University, vol. 20, no. 8, pp. 2307-2313, 2013.

[19] X. L. Yang and F. Huang, "Three-dimensional failure mechanism of a rectangular cavity in a Hoek-Brown rock medium," International Journal of Rock Mechanics and Mining Sciences, vol. 61, pp. 189-195, 2013.

[20] X. L. Yang, J. S. Xu, Y. X. Li, and R. M. Yan, “Collapse mechanism of tunnel roof considering joined influences of nonlinearity and non-associated flow rule," Geomechanics and Engineering, vol. 10, no. 1, pp. 21-35, 2016.

[21] X.-L. Yang and J.-H. Yin, "Slope stability analysis with nonlinear failure criterion," Journal of Engineering Mechanics, vol. 130, no. 3, pp. 267-273, 2004.

[22] S. Senent, G. Mollon, and R. Jimenez, "Tunnel face stability in heavily fractured rock masses that follow the Hoek-Brown failure criterion," International Journal of Rock Mechanics and Mining Sciences, vol. 60, pp. 440-451, 2013.

[23] J. H. Yang, S. R. Wang, Y. G. Wang, and C. L. Li, "Analysis of arching mechanism and evolution characteristics of tunnel pressure arch," Jordan Journal of Civil Engineering, vol. 9, no. 1, pp. 125-132, 2015.

[24] G. F. Wang, Tunnel Calculation (The Theory of JointDeformation), Chengdu Science \& Technology University Press, Chengdu, China, 1992. 


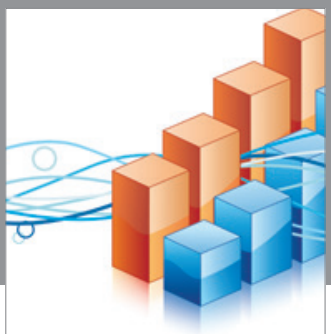

Advances in

Operations Research

vatem alat4

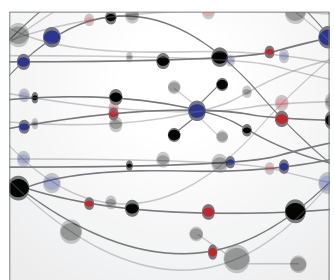

\section{The Scientific} World Journal
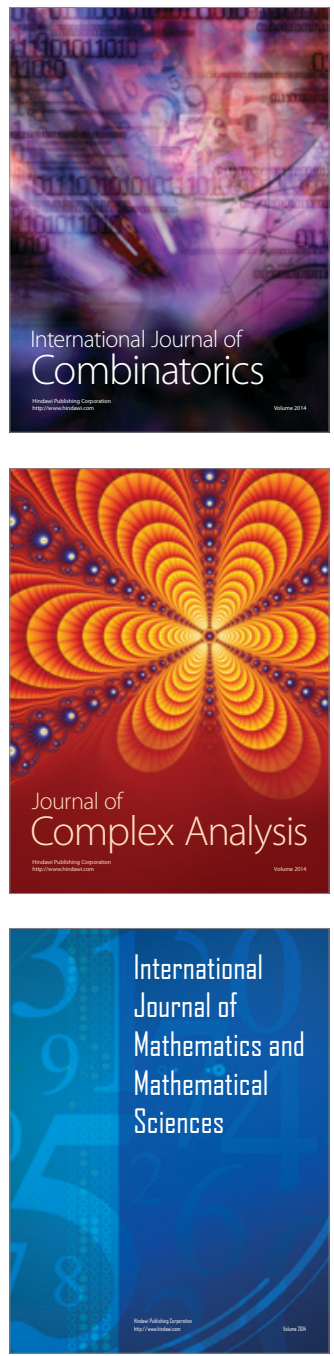
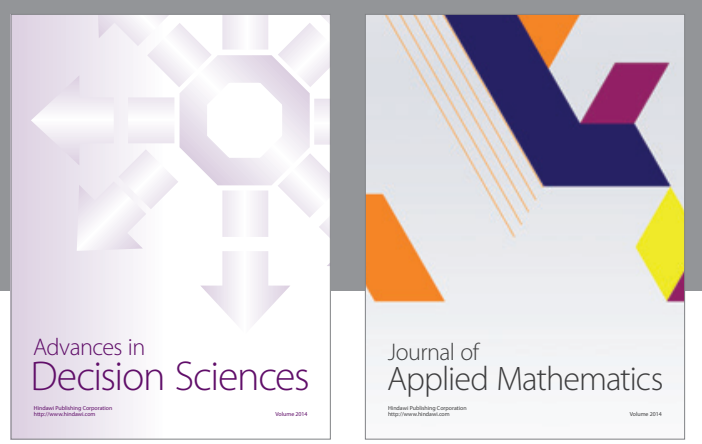

Algebra

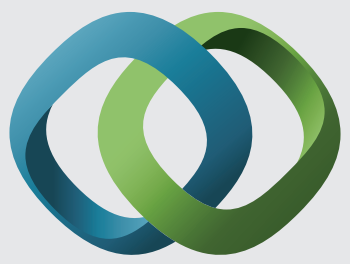

\section{Hindawi}

Submit your manuscripts at

http://www.hindawi.com
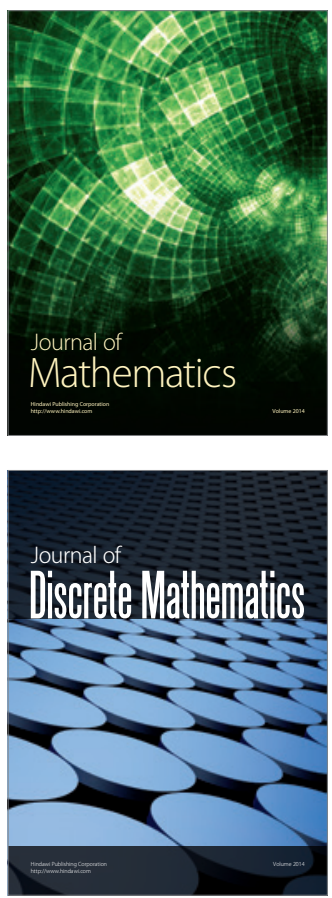

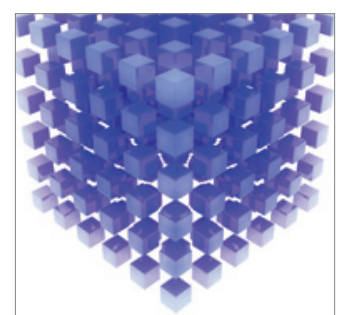

Mathematical Problems in Engineering
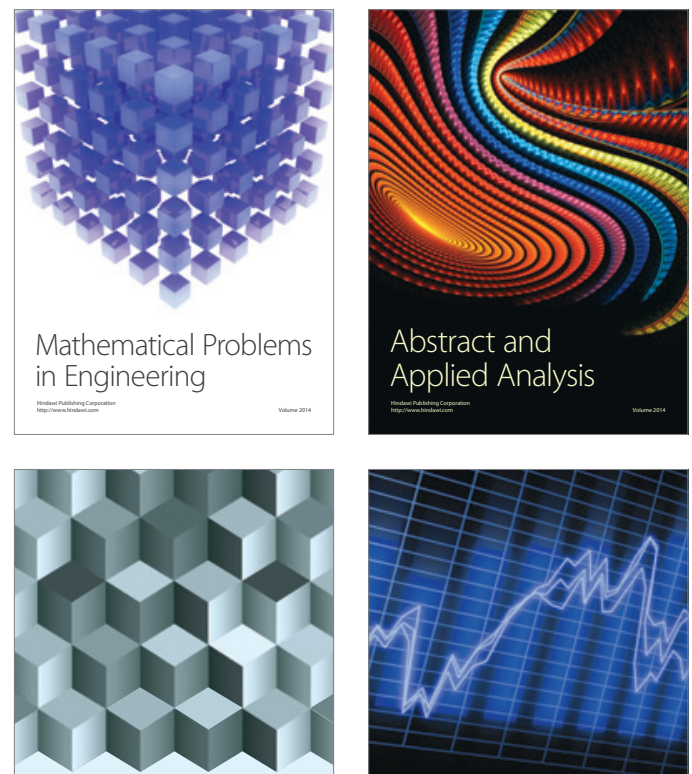

Journal of

Function Spaces

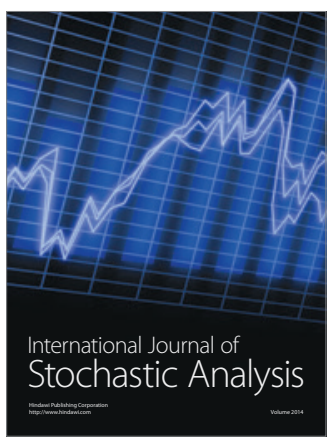

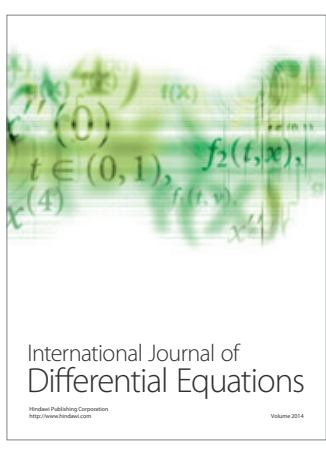
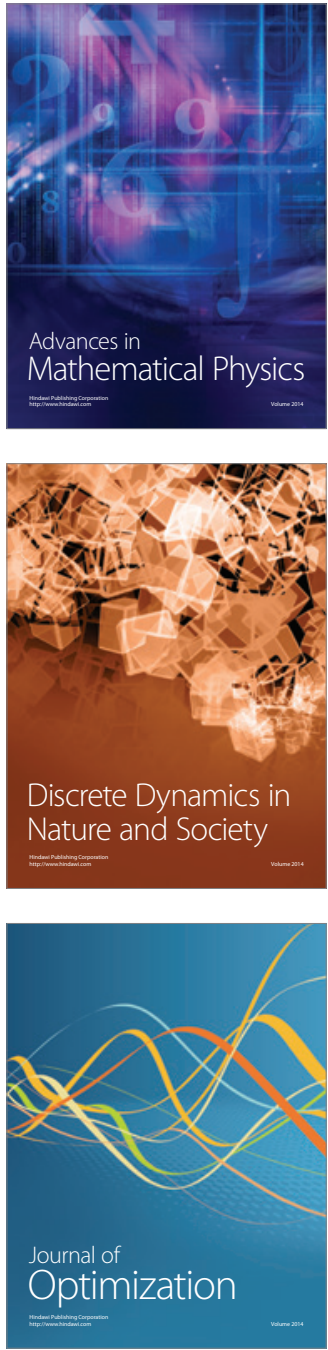